\title{
ACTIVE-ONLY CURRENT CONTROLLED SUMMING/DIFFERENCE AMPLIFIERS USING CCCIIS
}

\author{
SUDHANSHU MAHESHWARI* \\ Department of Electronics Engineering, Z.H . College of Engineering and Technology, \\ Aligarh Muslim U niversity, Aligarh - 202 002, India
}

(Received 28 December 2002; In final form 21 March 2003)

\begin{abstract}
Novel active-only summing/difference amplifiers employing only current controlled conveyors (CCCIIs) are presented. The circuits possess high input impedance, current controllable gain, good linearity and dynamic range, low THD and are suited for IC implementation. SPICE simulation results are included to verify the circuits.
\end{abstract}

Keywords: Active-only circuits; Current controlled conveyors

\section{INTRODUCTION}

A mplification is one of the fundamental signal processing applications. Conventional summing and difference amplifiers employ resistors that need to be varied for obtaining variable gain, which is often impractical especially if the circuit is to be fully integrated. Recently current controlled conveyors (CCClIs) have gained popularity as these devices provide high performance electronic functions operating either in voltage-mode or currentmode $[1,2]$. These conveyors offer a finite current controllable resistance at one of their ports $(X)$ that makes them an ideal choice for resistorless realizations [2]. If these devices are employed in amplifier circuits then active-only circuits with current controllability can be obtained. Such active-only realizations are ideal for monolithic implementation as no resistors are employed.

In this paper, active-only summing amplifier and difference amplifiers are proposed using CCClls only. Each circuit uses only three CCCIIs to realize the functions which are current controllable by varying the bias currents of the translinear conveyors $[1,3]$. The proposed circuits offer high input impedance, electronic adjustability, low distortions, and are suited for IC implementation. SPICE simulation results are included to confirm the theory.

\footnotetext{
* E-mail: maheshwarispm@ rediffmail.com
} 


\section{ACTIVE-ONLY CIRCUITS}

The current controlled conveyor (CCCII) is characterized by the following port relationship.

$$
\mathrm{i}_{\mathrm{y}}=0, \quad \mathrm{v}_{\mathrm{x}}=\left(\mathrm{v}_{\mathrm{y}}+\mathrm{i}_{\mathrm{x}} \mathrm{R}_{\mathrm{x}}\right), \quad \mathrm{i}_{\mathrm{z}}=\mathrm{pi}_{\mathrm{x}}
$$

where $p=1$ for $\mathrm{CCCII}+$ and $p=-1$ for $\mathrm{CCCII}-$. The proposed CCCII based summing/difference amplifier circuit is shown in Figure 1. Routine analysis of the circuit using Eq. (1) yields the following output voltage.

$$
\mathrm{V}_{0}=\mathrm{R}_{\mathrm{x} 3}\left(\frac{\mathrm{V}_{1}}{\mathrm{R}_{\mathrm{x} 1}} \pm \frac{\mathrm{V}_{2}}{\mathrm{R}_{\mathrm{x} 2}}\right)
$$

where $R_{x i}(i=1,2,3)$ is the intrinsic resistance at the terminal $X$ of the $i$ th conveyor and is given as:

$$
\mathrm{R}_{\mathrm{xi}}=\frac{\mathrm{V}_{\mathrm{T}}}{2 \mathrm{I}_{\mathrm{oi}}} \text {. }
$$

$\mathrm{I}_{0 \mathrm{i}}$ is the bias current of the ith current controlled conveyor [1]. In Eq. (2) the ' + ' sign corresponds to positive conveyor $(\mathrm{CCClI}+)$ and the circuit of Figure 1 realizes a summing amplifier whose gain can be controlled by varying the bias currents of the conveyors. It is evident from Eqs. (2) and (3) that the circuit easily provides a weighted sum of the two input signals. Similarly the ' - ' sign in Eq. (2) corresponds to negative conveyor (CCCII2-) and the resulting circuit then realizes a difference amplifier with current controllable gain. It is to be noted that the proposed active-only circuit(s) offer high input impedance

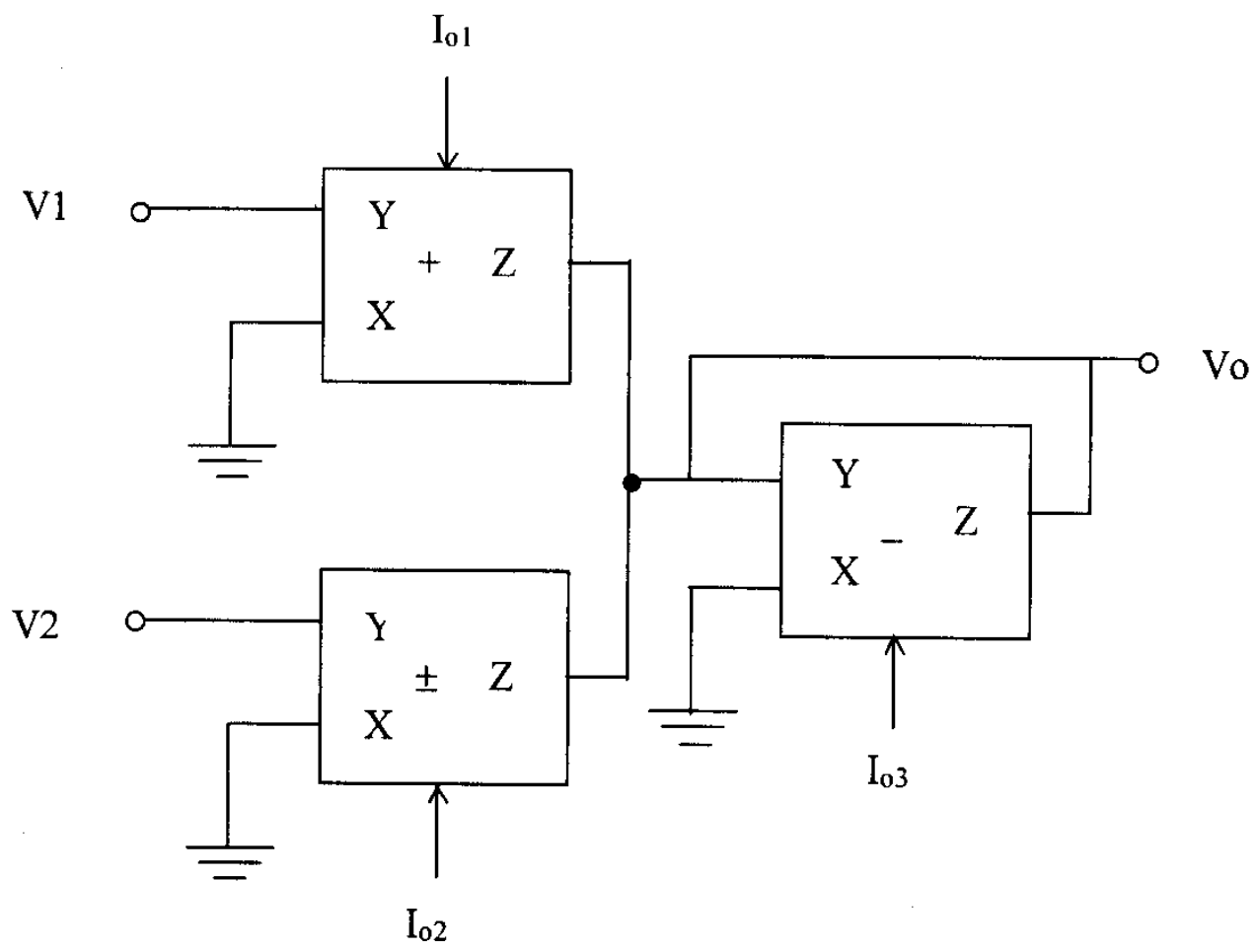

FIGURE 1 Proposed active-only summing/difference amplifier. 


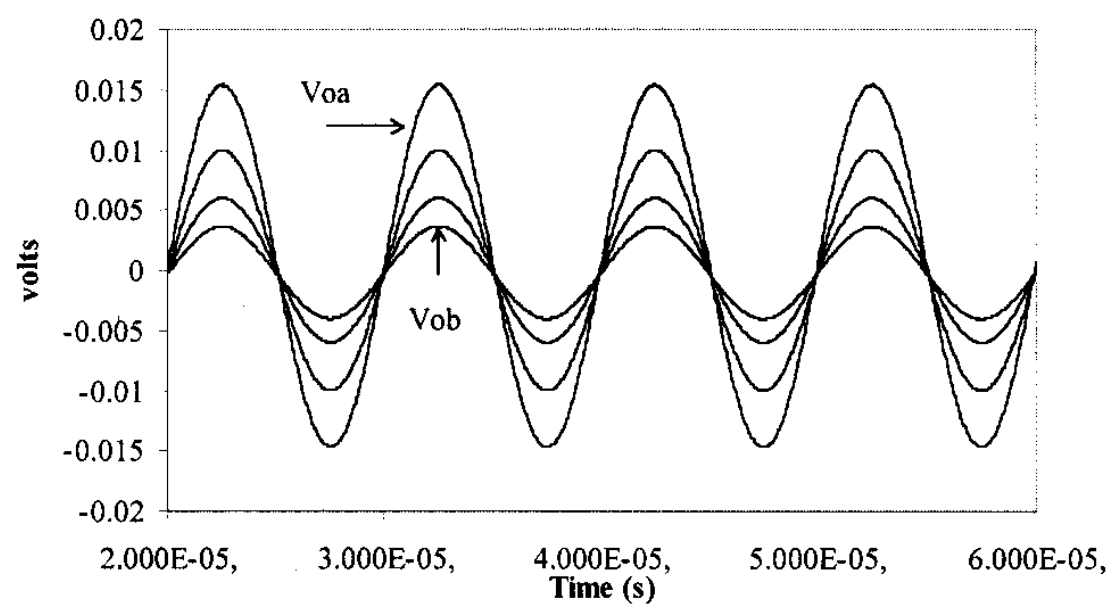

FIGURE 2 Time domain waveforms for summing (Voa) and difference (Vob) amplifier for $\mathrm{V}_{1}=10 \mathrm{mV}$ and $\mathrm{V}_{2}=6 \mathrm{mV}$.

and are suited for cascading in voltage-mode operation. As the circuit(s) employ no resistors they are also ideal for monolithic implementation.

\section{SIMULATION RESULTS}

To verify the proposed active-only circuit(s), bipolar implementation of CCCII is used for simulation [1,2]. Transistor model parameters of NR100N and PR 100N with a supply voltage \pm 2.5 volts are used for the simulation [4]. The active-only summing amplifier (with $\mathrm{CCCI} 2+$ ) of Figure 1 was designed for unity gain with equal bias currents of three conveyors as $100 \mu \mathrm{A}$. The two sinusoidal input signals of amplitudes $10 \mathrm{mV}$ and $6 \mathrm{mV}$, respectively and a frequency of $100 \mathrm{kHz}$ were used. Next the difference amplifier of Figure 1 (with CCCII2-) was simulated using the same values as for the summing amplifier. The time domain waveforms are shown in Figure 2, that shows the output amplitude as $16 \mathrm{mV}$

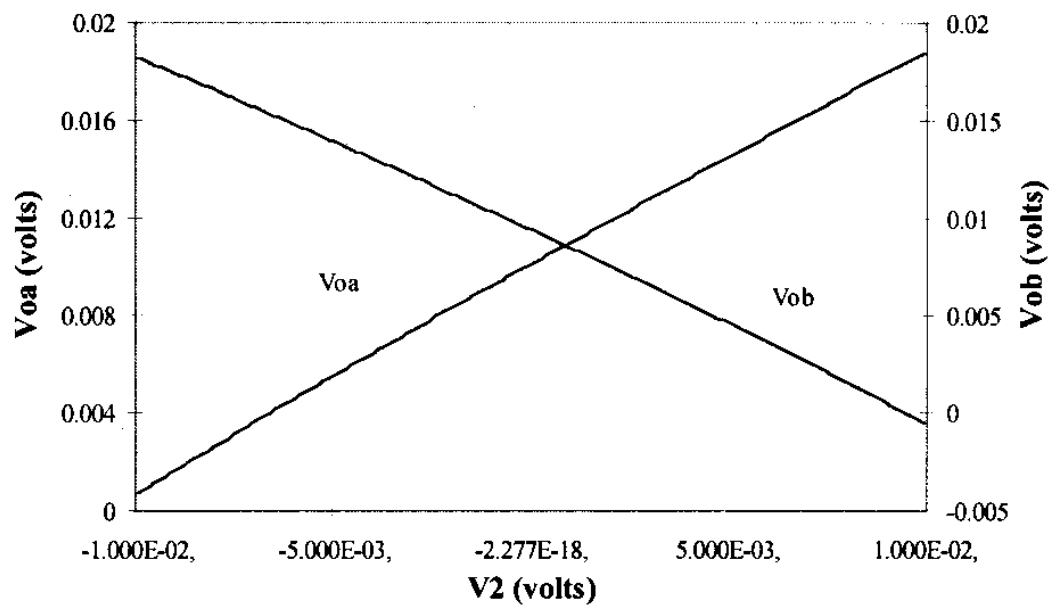

FIGURE 3 DC transfer characteristics for summing (Voa) and difference (Vob) amplifier for $\mathrm{V}_{1}=10 \mathrm{mV}$. 
(Voa) for the summing amplifier and $4 \mathrm{mV}$ (Vob) for the difference amplifier that is in conformity with the design. The output was found to show a total harmonic distortion (THD) of less than $1 \%$ for both summing and difference amplifiers that represent a low value. The summing/difference amplifier circuit was next simulated to study its dynamic range by applying a $D C$ input $V_{1}=+10 \mathrm{mV}$ and varying $V_{2}$ from $-10 \mathrm{mV}$ to $+10 \mathrm{mV}$ for the same values of bias current as above. The DC transfer characteristics as shown in Figure 3 for both the summing and difference amplifiers confirm a high degree of linearity and good dynamic range.

\section{CONCLUSION}

A novel active-only circuit using current controlled conveyors realizing summing and difference amplifiers is presented with features like electronic gain control, suitability for IC implementation, low THD, good linearity and dynamic range. Simulation results confirm the utility of the proposed active-only circuits.

\section{References}

[1] Fabre, A., Saaid, O., Wiest, F. and Boucheron, C. (1996). High frequency applications based on a new current controlled conveyor. IEEE Transactions on Circuits and Systems-II, 43, 82-91.

[2] A bu-elma' atti, M. T. and A I-qahtani, M. A . (1998). A current mode current controlled conveyor based analogue multiplier/divider. International J ournal of Electronics, 85, 71-77.

[3] K han, I. A. and M aheshwari, S. (2000). Simple first order all-pass section using a single CCII. International J ournal of Electronics, 87, 303-307.

[4] Frey, D. R. (1993). Log domain filtering: An approach to current mode filtering. IEE Proceeding G, Circuits D evices and Systems, 140, 406-416. 

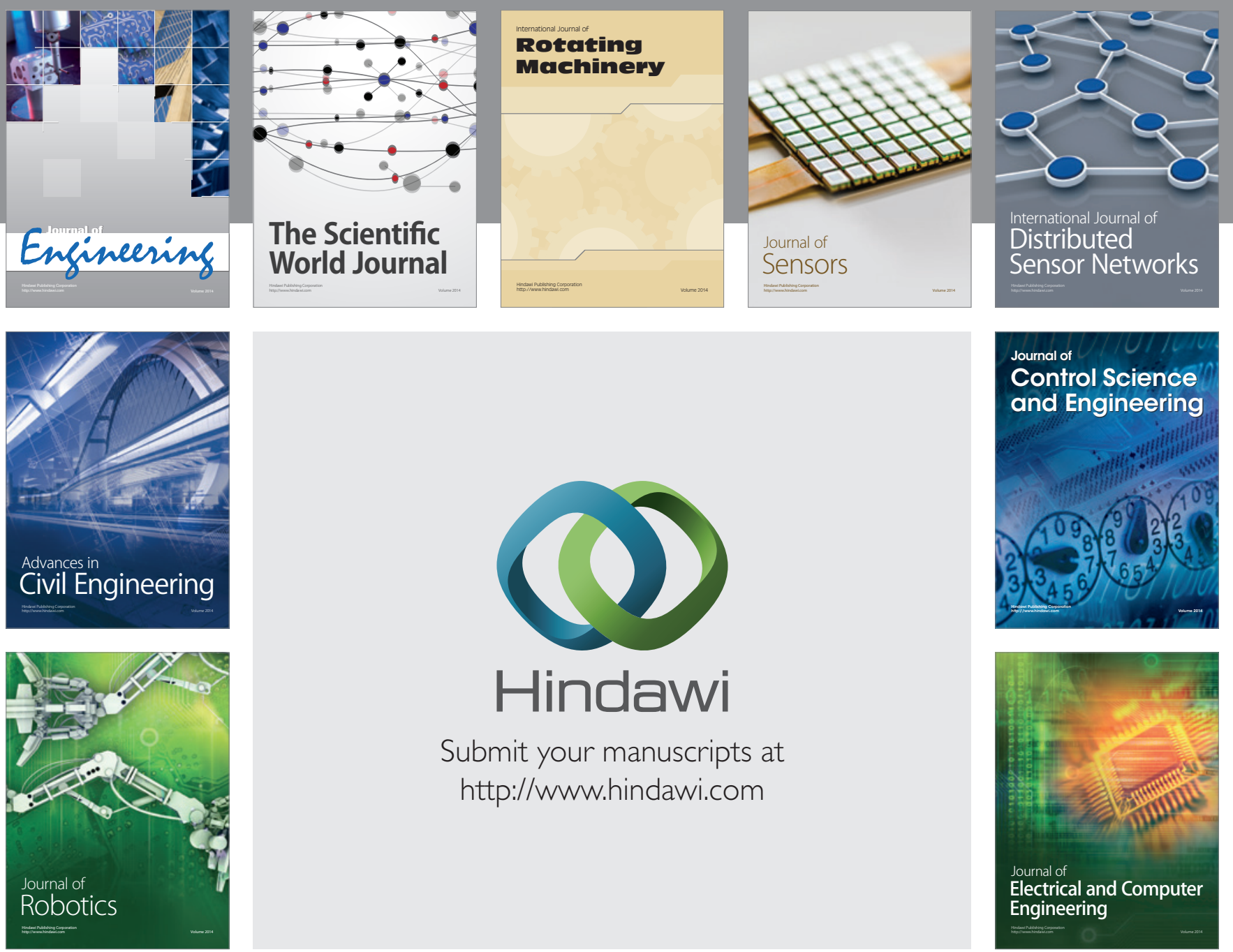

Submit your manuscripts at

http://www.hindawi.com
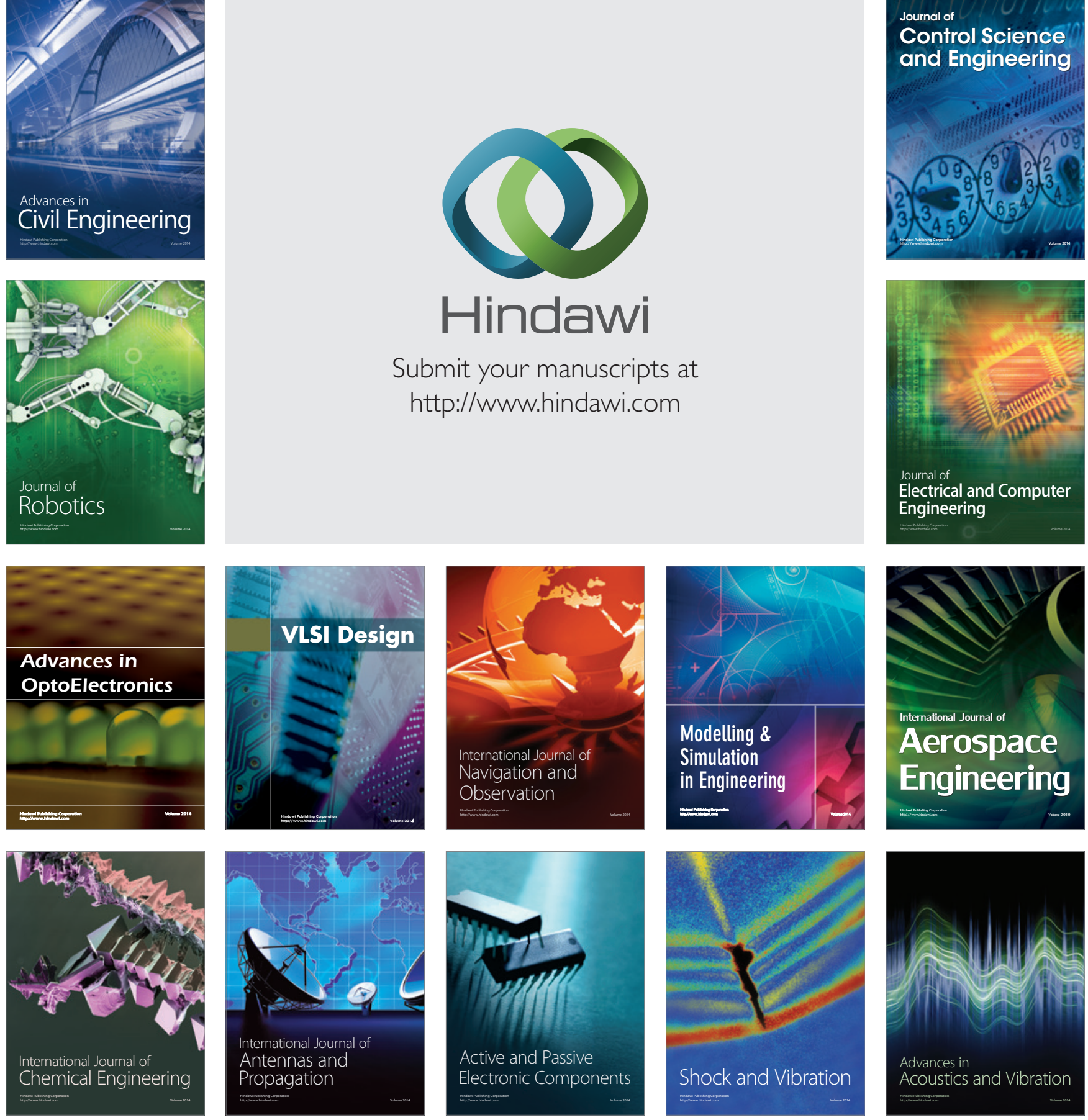